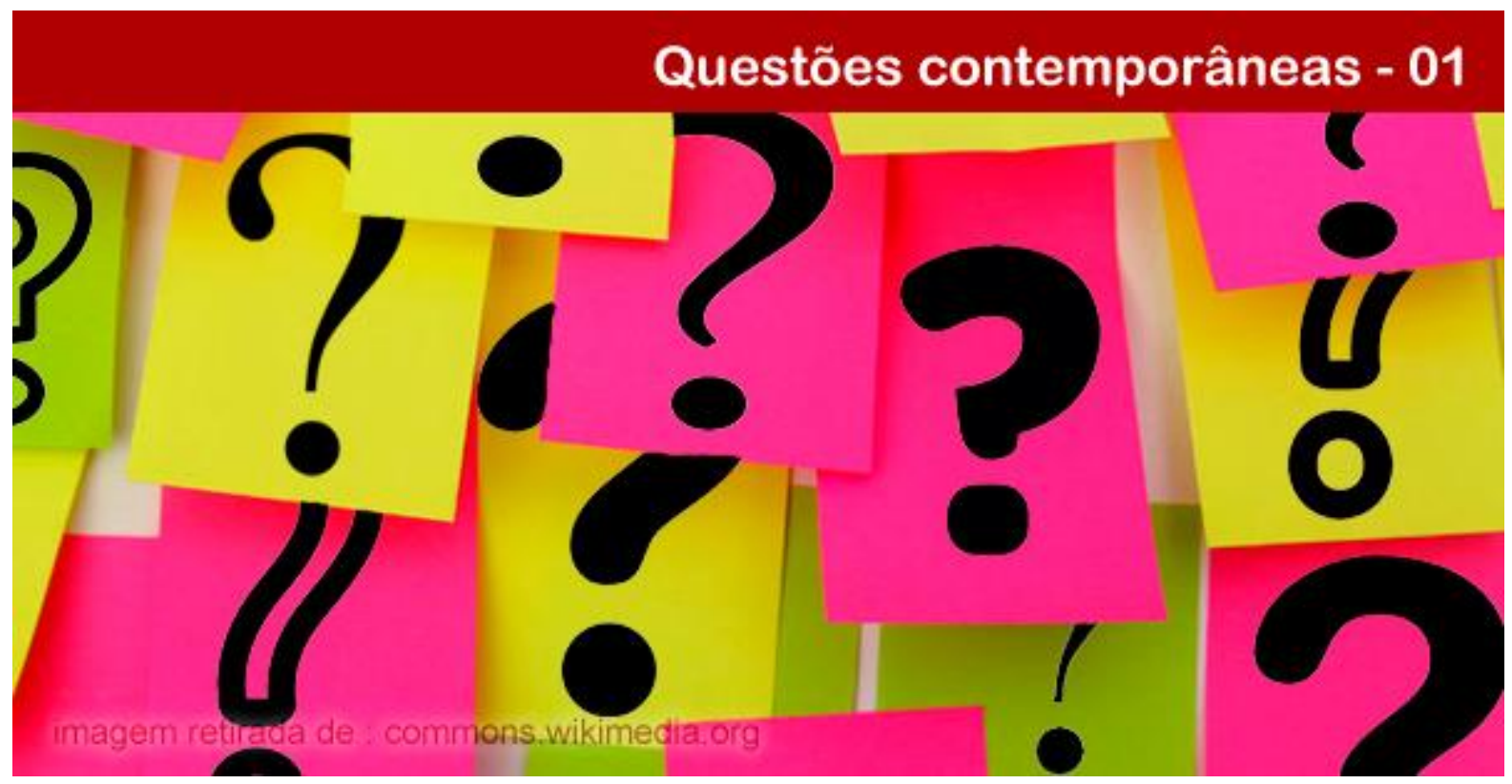

\title{
MODO OPERATIVO AND: TÉCNICA DE INVESTIGAÇÃO ABERTA
}

Francisco de Assis Gaspar Neto

Professor Adjunto da Faculdade de Artes da Universidade Estadual do Paraná (UNESPAR). Doutor em Teatro pela Universidade do Estado de Santa Catarina (UDESC) / Universidade de Lisboa, bolsista do programa de doutorado sanduíche. Mestre em Psicologia pela Universidade Federal Fluminense (UFF). Graduado em Artes Cênicas pela Universidade Federal do Estado do Rio de Janeiro (UNIRIO).E-mail: kikoneto@gmail.com.

Resumo: O artigo procura situar a prática do Modo Operativo AND (MO AND) dentro das técnicas de investigação aberta descritas por Gilbert Simondon, no final do quarto capítulo de Imagination et Invention (2014). Simondon descreve essas práticas inventivas como solução de problemas propostos pelo meio, através da modulação interna dos elementos intrínsecos ao conjunto que visa essa solução. Para tanto, o artigo demonstra os movimentos básicos de composição do Modo Operativo AND, apresentando as condições para essa prática que pode ser experimentada em realidades diversas, caracterizando o seu aspecto transversal.

Palavras-Chave: Modo Operativo AND. Zona de Atenção. Re-existência. Objeto Técnico. Técnicas de Investigação Aberta.

\section{MODUS OPERANDI AND: OPEN INVESTIGATION TECHNIQUES}

Abstract: This paper aims to contextualize the practice of Modus Operandi AND (MO AND) within the open investigation techniques described by Gilbert Simondon at the end of the fourth chapter of Imagination et Invention (2014). Simondon describes such practices as solution to the problems that came with the environment through the internal modulation of the intrinsic elements from the group that intends this solution. Therefore, the paper shows the basic movements of Modus Operandi AND composition, showing the conditions for this practice that can be experimented within diverse realities, characterizing its transversal aspect.

Keywords: Modus Operandi AND. Zone of Attention. Re-existence. Technical Object. Open Investigation Techniques.

\section{MO AND: investigação transversal}

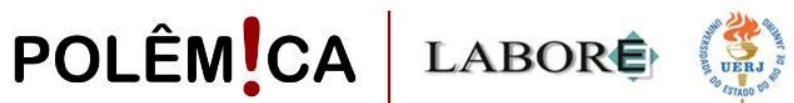

Polêmica - Revista Eletrônica da Uerj - Rua São Francisco Xavier, 524, $1^{\circ}$ andar bloco D, sl.1001 • Tels.: +55 21 2334-4088 / 4087 • http://www.e-publicacoes.uerj.br/index.php/polemica/index http://www.labore.uerj.br • laboreuerj@yahoo.com.br 
As formulações que deram origem ao Modo Operativo AND (MO AND) estão na tese de doutoramento da antropóloga e performer Fernanda Eugénio, intitulada Hedonismo Competente: Antropologia de Urbanos Afetos (2006). A tese analisa modos de existência que Fernanda Eugénio denomina de "e" e que mais tarde dará origem ao "and" do MO AND. No capítulo "O 'e' como estilo de vida: Etnopoética das sínteses disjuntivas", Fernanda Eugénio analisa um tipo de mutação subjetiva entre a juventude carioca na primeira metade dos anos 2000 que se evidencia em novos modos de experimentação com as drogas, com a sexualidade, com a música, na vida social e com os usos do corpo. Mesmo abrindo mão de regras transcendentes e prescritivas (tipo de regra geral e modelar valendo para todos), nem por isso as experimentações caem em algum tipo de relativismo; ao invés de obedecer à forma totalizante e excludente do "é" (é uma coisa ou outra, homem ou mulher, trabalhador ou vagabundo), ou a ausência de regras enunciadas por modos de existência sustentados precariamente no relativismo do "ou" (ou isso ou aquilo, espécie de tanto faz existencial), o hedonismo competente aponta para a construção de modos de existência que investem na composição entre diferenças, sem com isso deixar de avaliar a cada encontro os acordos que aumentam ou diminuem a potência de agir. Além de antropóloga, Fernanda Eugénio é uma artista que se dedica à performance situada, ao site-specific e à deriva urbana. Formada em dança pela escola Angel Vianna, no Rio de Janeiro, tem como norte da sua obra performática a criação de paisagens de encontros entre a arte e a antropologia que se estabelece no entendimento da etnografia como transversalização entre a arte e a ciência. Tanto na etnografia, quanto na produção artística, Fernanda Eugénio opera o que ela denomina de gesto de des-cisão (EUGÉNIO, FIADEIRO, 2012, 2013a), tornar a unir o que a tradição do pensamento ocidental separou como substâncias alheias umas às outras: sujeito e objeto, arte e ciência, corpo e pensamento. Já na introdução da sua tese, ela anuncia a tentativa de uma escrita científica não desvinculada da criação literária, resultando, em suas próprias palavras, em um método “indisciplinável, bem de acordo com a 'indisciplinada disciplina' que seria a antropologia nos termos de Geertz" (EUGÉNIO, 2006, p. 24).

Entre 2011 e 2014, Fernanda Eugénio colaborou com o dançarino e coreógrafo português João Fiadeiro, criador da técnica de Composição em Tempo Real. A Composição em Tempo Real emprestou ao MO AND a estrutura de uma experiência de longa duração em dança. João Fiadeiro é uma das figuras de destaque da chamada nova dança portuguesa,

\section{POLÊM!CA $\mid$ LABORË}


movimento que teve início no final dos anos 80. Após uma profunda experiência com o contato improvisação, Fiadeiro fundou, em 1990, a Companhia R.E.A.L, na qual se dedicou ao LAB/Projectos em movimento, espaço dedicado à transversalização entre disciplinas como ciência, filosofia, dança, performance. Já em 2008 deu início às pesquisas com a Composição em Tempo Real, método de escrita coreográfica que posteriormente transformou-se em "ferramenta transversal" para investigar a "(re)presentacão e a cooperação" (EUGÉNIO, FIADEIRO, 2013b, p. 1). À sua maneira, João Fiadeiro compartilha a mesma inquietação de Fernanda Eugénio a respeito das fronteiras disciplinares que separam a arte e a ciência. Inquietação que pode ser traduzida nas palavras da dançarina e coreógrafa Lisa Nelson (2009 apud COELHO, 2012, s/p), ao dizer que: “[...] dançamos para fazer explorações científicas. Criativo é aquilo que fazemos o dia todo".

No tempo em que estiveram juntos, Eugénio e Fiadeiro aprofundaram as pesquisas do MO AND no Atelier Real junto com outros artistas e pesquisadores em diversas áreas em um projeto que Fernanda Eugénio batizou de AND_Lab, laboratório de investigação cuja sigla significa Anthropology and Dance Laboratory, referindo-se ao mesmo tempo ao "e" do MO AND e acentuando a transversalidade do encontro entre as duas disciplinas. Desde 2014, Fiadeiro retomou as suas pesquisas coreográficas e de Composição em Tempo Real, no Atelier Real. Fernanda Eugénio, por sua vez, ainda vive em Lisboa e continua com as pesquisas do AND_Lab.

O MO AND pode ser descrito como uma técnica de investigação transversal cujo objetivo é a invenção sustentada de obras coletivas, podendo ser utilizada em várias realidades: uma conversa; uma construção em grupo; a formação de profissionais em diversas áreas; a criação de uma performance ao vivo, ou uma instalação; ensaios de um espetáculo de dança ou teatro, improvisações e até mesmo uma sessão de análise clínica. A noção de sustentabilidade faz desta prática um exercício de atenção ao que há a cada momento, convocando seus participantes a se posicionarem, tendo em vista a consistência do que está sendo gerido, assim como a do próprio coletivo. Nesta técnica, as soluções dadas de antemão não são suficientes para encontrar os caminhos pelos quais objeto e coletividade se sustentem; o coletivo precisa inventar estes caminhos, sendo necessário que haja coerência externa das ações, na criação e manutenção do objeto, e coerência interna, nas relações entre os elementos do coletivo. Assim, cada ação individual deve considerar a integração entre a sustentabilidade

\section{POLÊM!CA $\mid$ LABORË}


da composição (coerência dos objetos e seus funcionamentos) e a sustentabilidade dos elementos intrínsecos ao coletivo (ações, combinações, até mesmo a inatividade ${ }^{1}$ ). A própria dinâmica "e" impede que as soluções sejam elencadas a partir do plano individual (memória, opinião, desejo) e das formas socialmente consagradas (leis, regras, acordos préestabelecidos). Embora cada um participe a partir das suas perspectivas individuais, estas são moduladas pelas ações dos outros e pela dinâmica própria do objeto construído.

Os exemplos e esquemas apresentados aqui são recortes de modos possíveis de praticar o MO AND; existem muitos outros, inclusive os que prescindem de objetos e podem usar somente palavras, imagens ou movimentos. Como modo de aproximação suficiente, propõe-se aqui a descrição de um procedimento de composição denominado por Fernanda Eugénio e João Fiadeiro de escala maquete. Trata-se da observação laboratorial de encontros e relações disparados pelas ações dos participantes dentro do espaço de composição, utilizando materiais diversos, inclusive colocando a si mesmos como elementos, como numa improvisação teatral. Embora Eugénio e Fiadeiro tenham utilizado a palavra maquete, é possível também usar o termo plataforma, caracterizando um espaço qualquer que permita a atenção laboratorial aos modos emergentes de relação. Além disso, a plataforma pode ser tanto uma superfície concreta, uma mesa, por exemplo, quanto as condições que permitem a ocorrência de uma conversa, de improvisação em teatro, dança e música, ou também a organização de um grupo de trabalho reunido para a resolução de um problema. O que importa é que ela funcione como uma pínax, lâmina na qual os navegantes da antiguidade marcavam as descobertas de novos acidentes geográficos. A pínax passava de uma expedição à outra e a cada nova descoberta o mapa anterior ganhava novas marcas; deste modo a lâmina se modificava, da mesma forma que se modificavam as percepções coletivas sobre os relevos e os caminhos das navegações, sem que por isso as marcas anteriores fossem definitivamente apagadas. Mapa vivo que orientava para o futuro e plataforma para que novas inscrições fossem feitas sobre o passado, guardando as marcas de antigas explorações, ou como explica Simondon (2012, p. 22): “[...] no transcurso das sucessivas viagens, [a pínax] pode acolher novos detalhes, inseridos em meio aos antigos e ser prolongada para além das costas anteriormente exploradas". Para Simondon, a pínax expressa o nascimento de um modo de existência coletiva eminentemente transcultural porque dava lugar à livre troca de impressões

\footnotetext{
${ }^{1}$ Uma das ações mais importantes do MO AND é exatamente não participar, caso a situação esteja indo bem sem a sua ajuda (EUGÊNIO, FIADEIRO, 2012).
}

\section{POLÊM!CA $\mid$ LABORE}


entre os seus usuários e permitia, ao mesmo tempo, a coleção destas impressões e seu manuseio. Em um artigo recente (2016), Fernanda Eugénio diz preferir “modo lupa”, ao invés de escala maquete, para pensar a dinâmica da experiência laboratorial como modo de aproximação dos eventos diferente dos modos cotidianos. Estes dois sentidos conjugados, o de plataforma sempre em re-composição e o de instrumento de observação acurada, são, por sua vez, capazes de descrever a dinâmica da composição coletiva e o tipo de atenção necessária para a prática do MO AND.

\section{Composição em 3 movimentos}

O exemplo a seguir mostra os três movimentos iniciais do MO AND, necessários para encontrar as condições da composição coletiva. Na Figura 1, uma trena é posicionada e o que deve ser observado aqui não é necessariamente o objeto em si, mas também o modo como ele foi colocado, assim como as suas características naquele momento específico e sua função. Pense nesta posição como uma oferta para que os demais jogadores observem as qualidades que o objeto apresenta naquele momento, não aquilo que ele é, mas aquilo que nele há. No caso do objeto proposto, as suas características são: objeto de medição; retrátil; longo, achatado; amarelo; com números em preto; ligado a um compartimento na qual ele pode ser enrolado e guardado; atravessando o espaço de jogo em diagonal, marcando sua distância. Há muitas outras qualidades nesta ação, mas no exemplo em questão essas bastam.

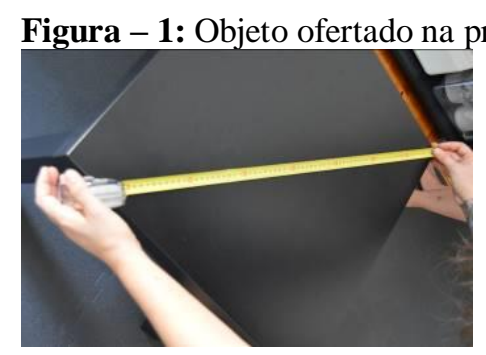

Fonte: Francisco Gaspar Neto (Acervo pessoal).

A primeira oferta serve como acidente inicial e abre o que Eugénio e Fiadeiro (2013b) chamam de zona de atenção. As possibilidades de contra-efetuar a primeira posição são determinadas, como já demonstrado, por suas qualidades e função e não pelo objeto em si. A partir dela cada participante constrói imagens mentais de possíveis posições.

\section{POLÊM!CA $\mid$ LABORE}


A Figura 2 mostra o momento em que outro objeto é ofertado, neste caso um timer, como contra-efetuação ao primeiro objeto proposto. Ao posicionar o segundo objeto, o segundo jogador corresponde a uma das possibilidades encontradas na primeira oferta (função de medição) e, ao mesmo tempo, aponta para uma possível condução da composição. Da multiplicidade de possibilidades presentes na primeira oferta, um participante escolhe o que apresenta mais potencial de manter a composição em funcionamento e posiciona outro objeto, ou modifica uma característica do que ali já está. Neste sentido, a segunda oferta cria a primeira relação. Cada um, neste momento, interrompe os mapas mentais, individuais, das possíveis contra-efetuações em resposta à primeira oferta e passa a corresponder à proposição feita pela primeira e segunda ofertas juntas, ou primeira relação.

Figura - 2: Objeto ofertado na segunda posição



Fonte: Francisco Gaspar Neto (Acervo pessoal).

A primeira e a segunda ofertas juntas correspondem à primeira relação encontrada. A terceira oferta deverá considerar esta primeira relação e não a primeira e a segunda ofertas separadamente. A terceira oferta define o tema da composição que é, ao mesmo tempo, o conjunto das primeiras regras do jogo. As regras imanentes de cada jogo dependem das condições, das relações e das qualidades que se apresentam nas 3 primeiras ofertas. Neste caso, a Figura 3 mostra que a composição caracteriza-se como livre troca de impressões a respeito das possibilidades do tema "medição": de espaço para a primeira oferta, de tempo para as outras duas. A terceira oferta, no exemplo em questão, tende a considerar mais a segunda oferta do que a relação entre as duas primeiras, mas a continuidade da composição permitiu um acerto nesta tendência. Neste caso, uma balança, como medidor de peso (Figura 4), foi ofertada na quarta posição enfatizando o tema "medição".

\section{POLÊM!CA $\mid$ LABORE}


Figura - 3: Terceira oferta e primeira relação entre relações



Fonte: Francisco Gaspar Neto (Acervo pessoal).

A terceira oferta segue o mesmo sentido da segunda, só que agora entre relações; ela corresponde à primeira relação, ao mesmo tempo em que aponta novas possibilidades dentro do mesmo tema. A composição, propriamente dita, irá se desdobrar respeitando sempre as relações já existentes e como uma investigação a respeito de um determinado tema. A Figura 4 mostra uma composição já em andamento, cujo tema continua sendo a medição.

Figura - 4: Composição em andamento

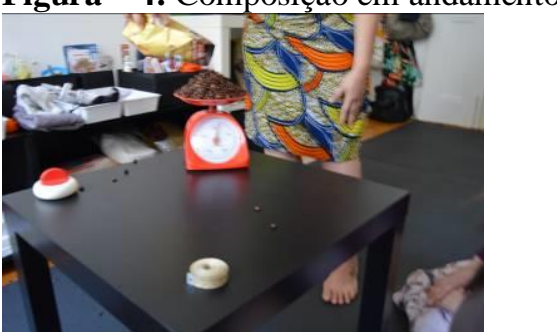

Fonte: Francisco Gaspar Neto (Acervo pessoal).

A palavra oferta vem sendo utilizada para falar da ação que cada participante executa ao colocar um objeto. O termo exato, no universo do MO AND é posição; cada objeto, ou ação, ofertado corresponde a uma posição. A decisão por usar a palavra oferta, neste primeiro exemplo, serve para enfatizar que cada posição é, ao mesmo tempo, uma oferta para a posição anterior, mostrando claramente ao coletivo qual das várias qualidades da posição anterior ela quer evidenciar e, ao mesmo tempo, uma oferta para a posição que virá. A ideia de plataforma se evidencia neste espaço-tempo entre duas ofertas; cada posição toma a relação anterior como plataforma para um salto na direção do futuro provisório da composição, tornando-se, ao mesmo tempo, plataforma para a próxima posição. A este ponto no qual em uma posição co-incidem plataforma e salto, Fernanda Eugénio e João Fiadeiro (2012, p. 62) batizaram de secalharidade, conceito originado de uma expressão que se usa em Portugal para dizer que as coisas estão de acordo ou à mesma altura, se calhar, se coincidir.

\section{POLÊM!CA $\mid$ LABORE}




\section{Secalharidade}

A secalharidade (EUGÉNIO, FIADEIRO, 2012), como conceito-ferramenta (EUGÉNIO, FIADEIRO, 2013b), nomeia a prática de criação coletiva e também o encontro suficiente com o acontecimento, além de definir o próprio encontro entre Eugénio e Fiadeiro, sendo o "conceito que nomeia, justamente, o modo de operar e habitar paisagens comuns que se desenhou na contaminação recíproca entre nossos conceitos e procedimentos" (2012, p. 61). O conceito propõe o abandono da manipulação como decisão pessoal, dando ao encontro a condição de criação de um plano comum e torna possível uma "assistência não expectante, desarmada do eu e atenta ao outro" (2012, p. 62). Eugénio e Fiadeiro (2012, p. 62) descrevem a secalharidade como "prática de improvisação e criação coletiva de paisagens de convivência", ou seja, a Composição em Tempo Real de João Fiadeiro, como prática de improvisação e atenção ao que há, e a Performance Situada de Fernanda Eugénio, como propositora de encontros coletivos, se posicionam criticamente em relação às práticas coreográficas e aos modos de organização hierarquizados nas relações coletivas, “interrogando, hoje, sobre seus habituais contra-discursos de resistência à cinética moderna sobre a suficiência destes em produzir e dar a ver o encontro criativo, a relação com o outro, a convivência e a colaboração" (2012, p. 62). Quando falam de paisagens de convivência, Eugénio e Fiadeiro apontam não somente para as relações entre indivíduos, pessoas, mas na emergência de modos de agir e de pensar que se instalam sobre uma tensão que permite a abertura para o mundo como processo de diferenciação para "visibilizar uma 'ética do comum', investigar formas de criatividade já não assentes na identidade radical do sujeito, do autor ou do artista, e lidar francamente com a questão do "viver juntos"” (2012, p. 62). É na experiência da secalharidade que se monta a maquinaria que faz funcionar o MO AND, "ou seja, a conversação entre diferenças de procedimento e operação que, por seguirem se diferenciando na medida do colocar e recolocar de problemas, façam emergir o encontro como relevo acidentado" (2012, p. 62). A secalharidade, assim, opera "a hipótese de sermos todos investigadores, bem como a hipótese da investigação ser capaz de gerar, sistematicamente e de modo imanente, o próprio território a ser investigado" (2012, p. 62).

Em 2015, em um encontro no AND_Lab, Fernanda Eugénio desenhou um esquema que permite visualizar o regime da secalharidade nas relações entre indivíduos. Trata-se do

\section{POLÊM!CA $\mid$ LABORE}


cruzamento de duas retas; a reta vertical encontra-se entre o polo do explícito e o do implícito, enquanto a reta horizontal fica entre o polo do aberto e o do fechado. As regras prescritivas do regime do "é" são as que se posicionam entre o aberto e o implícito, regras normativas que se expõem a todos, transcendentais, e que exigem obediência. As relações que se encontram no quadrante entre o implícito e o fechado são aquelas nas quais há pouca ou quase nenhuma abertura para o diálogo, vigendo somente a vontade e o ponto de vista individuais. É neste quadrante que Fernanda Eugénio identifica também a lógica relativista do "ou", na qual cada indivíduo transveste seu ponto de vista com a forma de lei. No quadrante entre o fechado e o explícito, organizam-se as regras dos pequenos grupos que, apesar de serem observadas por vários indivíduos, acabam funcionando do mesmo modo que no quadrante anterior. São regras culturais também que só podem ser reconhecidas por quem domina determinados códigos. Por sua vez, é no quadrante entre o aberto e o explícito que se encontra o modo de operação que sustenta as escolhas não por pressupostos, mas pela qualidade daquilo que o encontro oferece como potência imanente. Neste sentido, Eugénio e Fiadeiro (2013b) dizem que para todo saber há um sabor, um degustar que se demora sobre a experiência, que se alarga, aumentando assim a possibilidade de novos encontros no interior dele mesmo, e também um navegar ao seu sabor.

Eugénio e Fiadeiro (2013b) dizem que em Portugal há uma expressão muito comum que diz que as comidas sabem a alguma coisa, a forte, fraca, azedo, doce, assim como "este café sabe a amargo". É uma imagem bonita sobre a relação que se pode ter com os encontros e com os afetos, indagar-se primeiro o que eles têm de conhecimento próprio, o que têm a oferecer e aí sim deixar-se impregnar e acompanhar as vibrações em seus sentidos. Ao mesmo tempo, pode-se estar ao sabor do acontecimento, deixar-se levar pelo que ele sabe, e saborear como um modo de conhecimento. Este modo de relação atenta articula-se com o que Eugénio e Fiadeiro chamam de re-paragem, o exercício de parar e re-parar naquilo que há em cada situação. A re-paragem faz a passagem dos modos de operar as relações que indagam, de início, o "por que" ou o "quem" dos encontros para o modo de operação que parte "do quando-onde" (2013b) das condições através das quais um acontecimento começa a ganhar corpo.

\section{POLÊM!CA $\mid$ LABORE}


Figura - 5: Eixo das relações

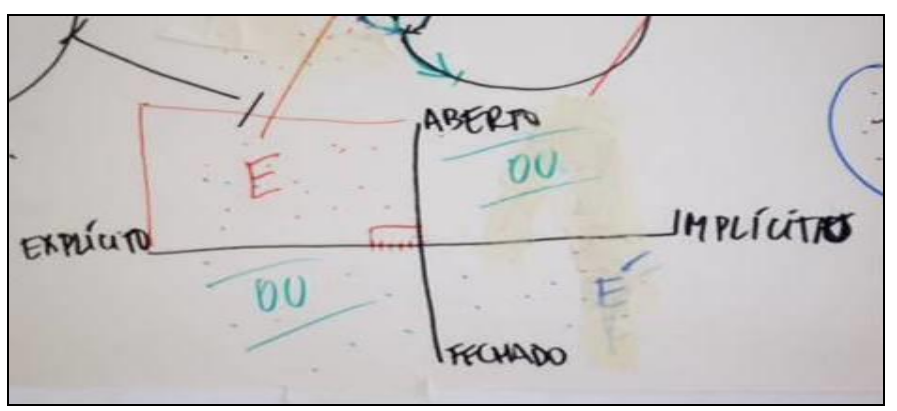

Fonte: Fernanda Eugénio (acervo AND_Lab).

\section{Re-existir: analogia do MO AND com a gênese do objeto técnico}

Fernanda Eugénio e João Fiadeiro (2012) dizem que a re-existência, diferentemente do ato de resistir ao outro, significa resistir "com" o outro e "no" outro. Colocar-se "com" é um modo de ampliar o tempo de vida próprio no tempo de existência do outro, aumentar sua potência no coletivo. Re-existir, portanto, é a decisão de colocar-se no quadrante entre o aberto e o explícito a cada vez. Nas imagens abaixo, a dançarina Lilian Gil capta o exato momento em que Simmel, o gato de Fernanda Eugénio, entra no espaço de composição e contra efetua o acidente. Na continuação, os demais jogadores oferecem um recipiente com comida para o gato e depois um prato com uma fruta para a dançarina.

Figura - 6: Re-existir
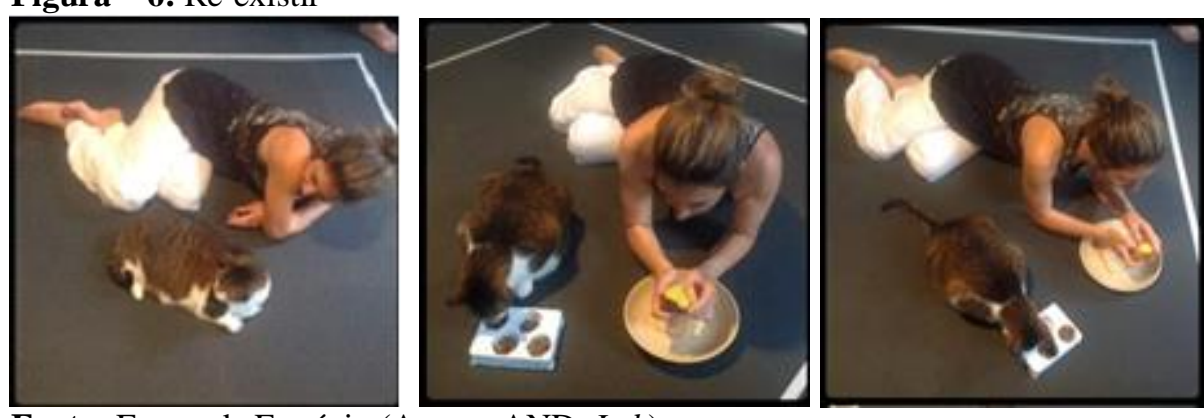

Fonte: Fernanda Eugénio (Acervo AND_Lab).

Retroativamente, o gato que estava sozinho no espaço torna-se companheiro da dançarina; em seguida, ela torna-se observadora do gato enquanto ele se alimenta; finalmente, eles tornam-se companheiros de almoço. Por um lado, a composição avança passo a passo, acolhendo novos elementos que reescrevem a narrativa do que ali já havia. Por outro, cada elemento recebe sua significação em função dos demais; é sempre em relação ao outro que

\section{POLÊM!CA $\mid$ LABORE}


uma função é vivida a cada momento. No contexto da Composição em Tempo Real, Fiadeiro (2008) diz que a grande fonte de mal-entendidos nesta prática é que os participantes costumam dar mais atenção aos objetos do que às funções que eles exercem a cada relação.

A analogia com a gênese do objeto técnico descrita por Simondon (1989) é capaz de definir o modo de funcionamento da composição e fazer o primeiro ponto de contato com as técnicas de investigação aberta que serão apresentadas mais adiante. Para Simondon (1989, p. 20): “[...] o objeto técnico individual não é tal ou tal coisa, dada hic et nunc, mas aquilo de que há gênese. A unidade do objeto técnico, sua individualidade, sua especificidade, são as características de consistência e de convergência de sua gênese". Primeiro, o objeto não é dado desde sempre, nem mesmo como uma ideia que irá se cumprir depois de uma operação que dará forma a ela; o objeto é a própria operação em seu devir e está presente em cada passo do seu processo: “O motor a gasolina não é tal ou tal motor dado no tempo e no espaço, mas o fato de que há uma sequência, uma continuidade que vai dos primeiros motores até estes que nós conhecemos e que estão ainda em evolução" (SIMONDON, 1989, p. 20). Em segundo lugar, a consistência do objeto técnico é composta pela ressonância interna dos seus elementos, como eles orientam mutuamente suas ações tendo em vista o funcionamento do todo: "O ser técnico evolui por convergência e por adaptação a si mesmo; ele se unifica interiormente segundo um princípio de ressonância interna" (1989, p. 20). Por fim, é ilusório, para Simondon, definir o objeto técnico por sua utilidade e tomar esse uso como modelo de sua existência: “as espécies são fáceis de distinguir sumariamente, para o uso prático, enquanto aceitamos apreender o objeto técnico pelo fim prático ao qual ele responde; mas trata-se aqui de uma especificidade ilusória, pois nenhuma estrutura fixa corresponde a um uso definido" (1989, p. 19). A essência do objeto técnico, portanto, reside no seu devir e na ressonância interna dos seus elementos, não em sua finalidade; confundimos a forma momentânea dos objetos com o objeto finalizado, quando, na realidade, ele é somente uma das etapas de uma evolução constante. Deste modo, sempre estamos nos relacionando com essa classe de objetos a uma certa altura, em um momento provisório de sua existência. A composição envolvendo o gato e a dançarina é análoga à formalização de um objeto técnico; cada nova posição faz avançar a composição em seu devir; os estágios que ela atravessa são intermediários entre uma estrutura anterior, que serve de base, e um futuro ainda incerto, mas

\section{POLÊM!CA $\mid$ LABORE}


não totalmente desconhecido. Esse devir, do qual conhecemos somente momentos provisórios, é o transbordamento da fase anterior.

No caso do MO AND, se o futuro não é dado de uma vez por todas, é a partir dos materiais e relações presentes a cada etapa que se encontram os caminhos pelos quais se pode inventar novos modos de re-existência. Outra analogia, ainda, pode ser encontrada entre a gênese do objeto técnico e o MO AND; trata-se do que Simondon (1989) denomina de concretização, conceito através do qual ele descreve um estágio de funcionamento do objeto técnico, um motor, por exemplo, no qual as partes tendem à compatibilidade de suas ações recíprocas: "O objeto técnico existe, portanto, como tipo específico obtido ao termo de uma série convergente. Essa série vai do modo abstrato ao modo concreto: ela tende para um estado que faria do ser técnico um sistema inteiramente coerente consigo mesmo, inteiramente unificado" (p. 23). Na fase abstrata, cada elemento funciona uma única vez no processo, sem entrar em contato com as demais etapas: "No motor antigo, cada elemento intervém em um certo momento no ciclo e depois presume-se que não age mais sobre os outros elementos; as peças do motor são como pessoas que trabalhariam cada uma à sua vez mas não se conheceriam umas às outras" $(1989$, p. 23). Cada elemento, na fase abstrata, é fechado e completo em si mesmo, totalmente orientado para a tarefa que deve executar, agindo como partes extra partes (SIMONDON, 1989). Já na fase concreta, a estrutura do objeto avança através da convergência das partes, como foi demonstrado acima.

A analogia com a composição no MO AND se completa neste ponto; de início existiam duas figuras, o gato e a dançarina, funcionando como "partes extra partes"; quando a dançarina capta o momento oportuno para se deitar ao lado de Simmel, o gato, este ato marcou a fase abstrata da composição; é no momento em que os pratos com comida são inseridos que a fase de concretização tem início, estabelecendo a ressonância interna da composição. Abstraindo o processo de concretização do objeto técnico para o modo de funcionamento do MO AND, pode-se dizer que ele se caracteriza pela passagem do modus operandi abstrato para o concreto.

\section{MO AND: técnica de investigação aberta}

No final do capítulo quatro de Imagination et Invention (2014), Simondon descreve as características de técnicas que facilitam a criação coletiva. De início, ele as diferencia

\section{POLÊM!CA $\mid$ LABORË}


daquelas que ordenam as contribuições individuais na criação coletiva a partir da finalidade e de "maneira unidirecional, em vista de um resultado [...]" (p. 184). Nas técnicas de facilitação descritas pelo autor, o papel de cada uma das partes não é definido por regras anteriores e exteriores à própria experiência; nelas, o objetivo é estreitar a sinergia entre os subconjuntos, aumentando o nível de compatibilidade, e isso só é possível se o foco da atenção estiver no processo, nos modos de produção e distribuição das forças empregadas, e não na finalidade. Através da criação de soluções para problemas comuns ao grupo, cada indivíduo se vê obrigado a encontrar novas relações entre o que lhe é ofertado e os modos suficientes de correspondência; isso faz com que o grupo crie a si mesmo, na medida em que cada indivíduo corresponde, a seu modo, com seus referenciais históricos e idiossincrasias a problemas colocados para o coletivo; o grupo encontra as soluções dos problemas dentro das dimensões nas quais eles são propostos e a partir das tensões internas das problemáticas em questão. Descartam-se, assim, as regras nascidas do desejo individual ou das normas socialmente consagradas. As únicas regras válidas são aquelas constituídas pelo próprio fazer coletivo, concretamente, como condição e não como condicionamento, como dizem Eugénio e Fiadeiro (2013a). Neste contexto, as técnicas de investigação aberta se enunciam por regras negativas ou positivas; as negativas são críticas porque subtraem os caminhos habituais pelos quais um problema é abordado. Já as positivas operam transformações nas abordagens: tentativa de soluções inversas às habituais, supressão de um elemento ou troca de papéis.

Em resumo, nas técnicas de investigação aberta a ideia de abertura se repete em dois planos; o primeiro é relativo ao encontro entre sujeitos em abertura para a experiência e não entre indivíduos fechados; o segundo diz respeito ao fato de que as soluções ultrapassam as problemáticas que lhe deram origem. As soluções apresentam abertura para o ambiente, sendo capazes, assim, de agregar outros componentes em sua estrutura. Aqui, o coletivo não deve ser tomado como um agregado de indivíduos partes extra partes; primeiro, porque cada um carrega consigo uma parcela de realidade pré-individual da qual se origina: "Não é certamente enquanto indivíduo que os seres se relacionam uns com os outros no coletivo, mas enquanto sujeitos, quer dizer, enquanto seres que contém algo da ordem do pré-individual" (SIMONDON, 2015, p. 394). O indivíduo é parte relativa de uma realidade que transborda suas fronteiras, uma natureza não formalizada. O que o indivíduo tem em comum, no plano coletivo, é o incomum, já que o pré-individual não pode ser dito dele, mas participa de sua

\section{POLÊM!CA $\mid$ LABORË}


existência como "mais do que ele mesmo" (COMBES, 2013, p. 3). A natureza pré-individual que não pode ser formalizada em cada indivíduo ganha no coletivo a estrutura na qual ela pode se atualizar. O que existia no plano pré-individual somente como sinal, ganha significação na experiência coletiva, ou como diz Paolo Virno (2011, p. 404): “[...] o desafio consiste em imprimir uma forma contingente e inconfundível ao apeiron (indeterminado), isto é, à 'realidade do possível' que precede a singularidade, ao universo anônimo da percepção sensorial, ao "pensamento sem portador"'. No MO AND, por exemplo, um participante pode obter da relação com os outros e com os objetos significações que não teria sido capaz de perceber por si só. É como o violoncelista do qual Virno dá o exemplo, que “interagindo com os outros artistas executantes, retira da sua própria partitura algo que até então lhe tinha escapado" (2011, p. 404).

\section{Noz somos}

Figura - 7: Noz Somos.

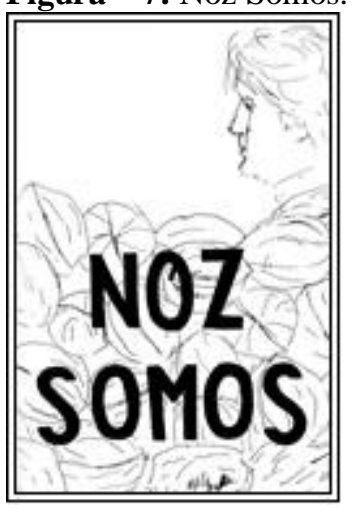

Fonte: Rita Draper Frazão. Disponível em: <http://innertour.blogspot.pt/2015/07/and-this-song-offreedom.html>.

O desenho da Figura 7, feito pela artista visual portuguesa Rita Draper Frazão, durante uma sessão de MO AND em Lisboa, ilustra o que vem sendo tratado até agora. Com singular sensibilidade, Rita representou os temas discutidos neste trabalho. No desenho, o acento da vogal "o" virado para dentro na palavra "noz" é uma pequena diferença incluída no desenho, que funciona como uma abertura, uma linha de fuga que já enuncia a tensão entre dois universos em disparidade, estabelecida pelas próprias condições da composição. Junto com o desenho, Rita apresenta a seguinte descrição:

\section{POLÊM!CA $\mid$ LABORE}


Em um determinado momento do jogo, as nozes foram usadas como um objetoferramenta de um código para expressar uma relação. Francisco Gaspar Neto teve um papel ativo nela, e eu fiz seu retrato com uma mordaça linguística: Nós Somos (estamos, em Português) soa praticamente o mesmo que Noz Somos (mas Noz significa noz, não nós!). Se alguém escreve wallnuts em Português, isso seria Nozes somos, então eu quero deixar claro que a minha escrita errada foi conectada a NOS, mas eu incorporei o acento na vogal o (que não existe no noz) como uma referência a isso. Metaforicamente falando, esta pequena gag poderia se traduzir nas "nozes" da vida - ações - que nós incorporamos como tijolos de um relacionamento, uma "parede de nozes". (FRAZÃO, 2015, s/p)

O enunciado de Rita Draper Frazão retrata especificamente o modo como a composição se desenrolou na tensão entre a retirada sistemática das nozes do espaço e a resistência resultante do desejo que elas retornassem; durante todo o tempo, algumas posições seguiam no sentido de ocultar as nozes, ou mesmo retirá-las, posições que seguiam uma lógica que pendia para critérios individuais; outras eram por falta de atenção à dinâmica que estávamos seguindo. De alguma maneira, as decisões tomadas no sentido de fazer com que as nozes permanecessem, impediam que a composição terminasse por causa de excesso de diferença. Manter a composição é, ao mesmo tempo, manter o coletivo, assim como manter a compatibilização interna do grupo. No decorrer da experiência, e com as nozes desparecendo e reaparecendo regularmente, a ideia de re-existência também se confundiu com uma certa ideia de resistência ao outro e é neste contexto que se formou uma parede de nozes; por outro lado, como a resistência não chegou ao ponto de se tornar um impeditivo da composição, a comunidade estava durante o tempo todo reexistindo à sua catástrofe.

\section{Conclusão}

Em entrevista concedida a Jean Le Moyne, em 1968, intitulada Entretien sur la mécanologie, Simondon (1968) considera como condição essencial para o objeto técnico, assim como para o ser vivente, que ele seja viável, ou seja, que a relação entre as partes que constituem tal objeto, ou ser, não seja "autodestrutiva". A ausência de estabilidade levaria o conjunto à não existência; entretanto, a estabilidade completa impede o funcionamento do mecanismo ou organismo, o que por sua vez também impede a sua existência. $O$ funcionamento ideal é aquele no qual a dose certa de estabilidade ou instabilidade mantenha o funcionamento viável. Traduzindo para o universo do MO AND, as regras prescritivas do regime "é" levam o funcionamento da ação coletiva à estabilização completa, simples

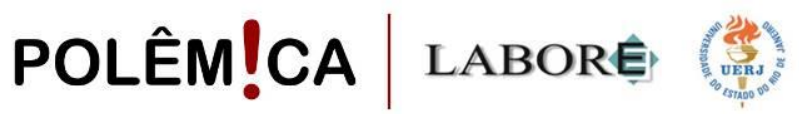

Polêmica - Revista Eletrônica da Uerj - Rua São Francisco Xavier, 524, $1^{\circ}$ andar bloco D, sl.1001 • Tels.: +55 21 2334-4088 / 4087 • http://www.e-publicacoes.uerj.br/index.php/polemica/index http://www.labore.uerj.br • laboreuerj@yahoo.com.br 
reprodução do que já havia sido ordenado, enquanto as ações nascidas de impulsos eminentemente individuais levam à completa instabilidade, ao relativismo. O regime do "e" encontra-se no ponto no qual as ações insiram doses de diferença e repetição que mantenha a viabilidade da composição. No contexto do MO AND, isso significa que cada participante tem que medir a suficiência das suas ações para inserir doses de estabilidade ou instabilidade de maneira a não inviabilizar o funcionamento da composição. Eugénio e Fiadeiro (2013b) explicam que no MO AND a ideia de controle por parte dos sujeitos, considerada por eles como exercício de manipulação, é transferida para a ética do manuseamento suficiente. Ao usar o termo manuseamento, os autores procuram se diferenciar da prática da manipulação, que por sua vez desconsidera as potências que circulam nos encontros com outros humanos, objetos e situações. O essencial neste modo de pensar os encontros é que a suficiência está atrelada à sustentabilidade, ou seja, só é possível um encontro realmente sustentável se as partes envolvidas corresponderem suficientemente ao que é proposto pelo outro e pela situação, inserindo doses de estabilidade ou instabilidade que não impeçam o funcionamento do que está sendo construído. Embora cada um participe através das suas perspectivas individuais, elas são moduladas pela ação dos demais e pela constituição aqui e agora do objeto construído. Na composição, cada nova posição faz com que ela avance em seu devir; os estágios que ela atravessa são intermediários entre uma estrutura anterior, que serve de base, e um futuro ainda incerto, mas não totalmente desconhecido. Esse devir, do qual conhecemos somente momentos provisórios, é o transbordamento da fase anterior; por isso, no caso do MO AND, se o futuro não é dado de uma vez por todas, é a partir das relações presentes a cada etapa que se encontram os caminhos pelos quais se pode inventar novos modos de re-existência.

\section{Referências}

COELHO, S. P. Os Tuning Scores de Lisa Nelson In: Programa de Go de Lisa Nelson e Scott Smith, Ciclo Improvisações/Colaborações. Porto. Auditório da Fundação de Serralves. Lisboa, 2012. Documento cedido por Silvia Pinto Coelho.

COMBES, M. Gilbert Simondon and the philosophy of the transindividual. Massachussets: Massachusetts Institute of Technology, 2013.

DEPRAZ, N., FRANCISCO J. VARELA; VERMERSCH, P. On Becoming Aware: A Pragmatics of Experiencing. Philadelphia: John Benjamins North America, 2003.

\section{POLÊM!CA $\mid$ LABORE}


DUENHA, M. L.; EUGÉNIO, F.; DINGER, A. Entre-modos. Um jogo de re-perguntas à volta do Modo Operativo AND. Urdimento - Revista de Estudos em Artes Cênicas. Universidade do Estado de Santa Catarina. Programa de Pós-Graduação em Teatro, Florianópolis, v.2, n.27, p.96-123, dez. 2016.

EUGÉNIO, F. Hedonismo competente: antropologia de urbanos afetos. 2006. Tese (Doutorado). Programa de Pós-Graduação em Antropologia Social do Museu Nacional, Universidade Federal do Rio de Janeiro, Rio de Janeiro, 2006.

EUGÉNIO, F.; FIADEIRO, J. Secalharidade como ética e como modo de vida: o projeto AND_Lab e a investigação das práticas de encontro e de manuseamento coletivo do viver juntos. Urdimento - Revista de Estudos em Artes Cênicas / Universidade do Estado de Santa Catarina. Programa de Pós-Graduação em Teatro, Florianópolis, v. 1, n. 19, p. 61-69, nov. 2012.

O encontro é uma ferida. Lisboa: GHOST, 2013a.

O Jogo das Perguntas. Lisboa: GHOST, 2013b.

FIADEIRO, J. Composição em Tempo Real. 2008. Disponível em:

<http://www.laportabcn.com/laportabcn/MostrarFichero.do?id=567〉. Acesso em: 20 dez. 2014.

FRAZÃO, R. D. AND, This song of freedom. Disponível em: <http://innertour.blogspot.pt/2015/07/and-thissong-of-freedom.html>. Acesso em: 10 ago. 2015.

SIMONDON, G. Du mode d'existence des objets techniques. Paris: Aubier, 1989.

Imagination et Invention. Paris: PUF, 2014. 2015.

La Individuación a la luz de las nociones de forma y de información. Buenos Aires: Cactus ed.,

Entretien sur la mécanologie, conversa registrada por Jacques Parent entre Gilbert Simondon e Jean Le Moyne em agosto de 1968. Disponível em: 〈https://www.youtube.com/watch?v=kCBWTHjKvbU〉. Acesso em: 14 set. 2016.

TARDE, G. Monadologia e Sociologia (e outros ensaios). São Paulo: Cosac Naify, 2007.

VIRNO, P. Multidão e o princípio de individuação. In: NEVES, Bruno P. Dias Neves (coord.). A Política dos Muitos. Lisboa: Tinta da China, 2011.

Recebido em: 03/05/2016.

Aceito em: 02/01/2017.

\section{POLÊM!CA $\mid$ LABORE}

Polêmica - Revista Eletrônica da Uerj - Rua São Francisco Xavier, 524, $1^{\circ}$ andar bloco D, sl.1001 • Tels.: +55 21 2334-4088 / 4087 • http://www.e-publicacoes.uerj.br/index.php/polemica/index http://www.labore.uerj.br • laboreuerj@yahoo.com.br 